\title{
PAINLESS CARDIAC INFARCTION
}

\author{
BY \\ WILLIAM EVANS AND GEORGE C. SUTTON
}

From the Cardiac Department of the London Hospital

Received July 29, 1955

It is tradition to associate coronary arterial disease with pain behind the breast bone. It is also known that pain may be absent when such coronary disease, even in a gross form, has not caused injury to the myocardium. What has not received the same universal recognition is that frank cardiac infarction from coronary occlusion can be present without invoking chest pain.

Gairdner (1891) applied the designation angina pectoris sine dolore to patients supposedly without actual pain, but with angor animi and a sense of impending dissolution. Obrastzow and Strascheskow (1910) mentioned that infarction of the heart could take place without causing pain, while Gallavardin in 1921 stated that patients may die of cardiac infarction without ever suffering pain.

In order to facilitate the diagnosis of cardiac infarction when pain is absent, and so apply appropriate treatment early in the illness, there is need to know the circumstances under which it is met. The purpose of this paper is to study this clinical syndrome and to promote a better understanding of it.

\section{THE INVESTIGATION OUTLINED}

Before patients could qualify for admission into the series that we assembled as examples of painless cardiac infarction, we required that four conditions should be satisfied. First, apart from insisting upon freedom from frank pain in the chest, it was necessary for each patient to deny the presence of like symptoms which included an ache, tightness, a sense of pressure, indigestion, and discomfort. Secondly, the patient had to testify to the absence of these symptoms following direct questioning when the observer's hand was laid on the chest to suggest where the abnormal sensation might have been felt. Thirdly, such close questioning had to take place soon after the start of the illness and at the same time corroboration of the patient's denial of chest pain was sought from a relative, a friend, or attending physician. It became evident early on that any neglect to exercise such care in the selection of patients would have meant the admission of many that were not true examples of painless cardiac infarction. The fourth condition was the finding of an electrocardiogram that showed the marks of cardiac infarction; in patients who died such infarction was sought at necropsy and in each of 11 patients so examined, cardiac infarction was present. Two circumstances contrived to make the electrocardiographic diagnosis difficult. One was the association in so many of left ventricular preponderance from arterial hypertension with a laterally situated infarct; the other was the presence of an arrhythmia which often obscured the changes in the tracing that were the outcome of cardiac infarction.

When such criteria were applied to patients examined in hospital and in private practice during five years, it was possible to assemble 70 examples of painless cardiac infarction, 56 men and 14 women. 


\section{Circumstances Favouring the Absence of Pain in Cardiac Infarction}

When the symptoms and signs presented by the patients who form this series were examined, there came to light certain circumstances that appeared to decide the absence of pain in cardiac infarction, a condition that characteristically gives rise to a pain often strong enough to cause its host to feel faint unless its sharpness has been subdued by morphine. These circumstances, which are summarized in Table I, will now be considered in turn.

TABLE I

InCidence of Circumstances appearing to determine the Absence of Pain in 70 Patients with Cardiac INFARCTION

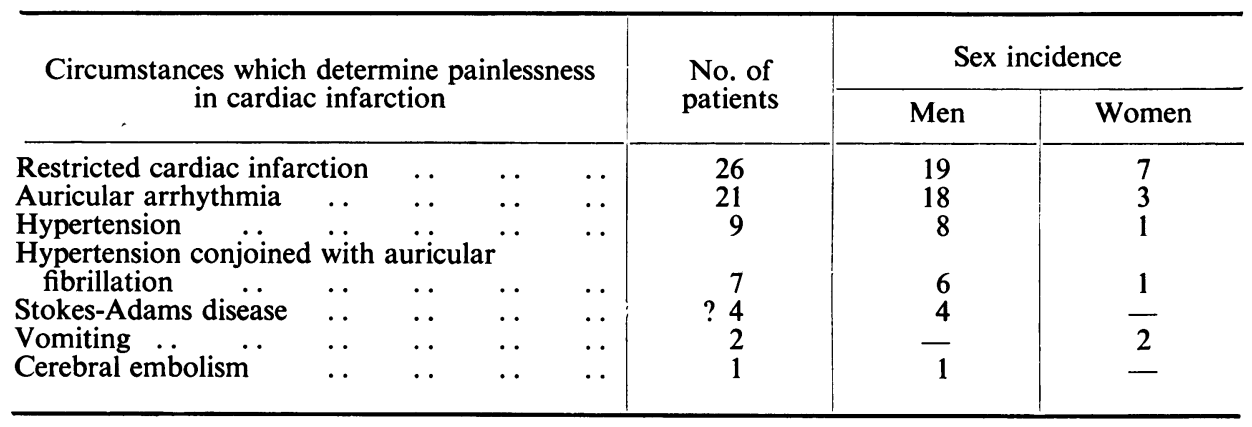

\section{AURICUlar ARrhythmia}

In this group of patients with painless cardiac infarction all showed auricuiar fibrillation, flutter, or tachycardia and those with associated hypertension or with heart block were kept apart.

Among the 70 patients, 21 qualified to enter this group, 18 men and 3 women. The average age was 59 years. In 12 the arrhythmia was auricular fibrillation while in 9 it was auricular tachycardia. In 3 patients the abnormal rhythm was of the paroxysmal kind, and in one other, auricular tachycardia changed to fibrillation and this continued as the dominant rhythm. In no patient in this group was syncope a symptom so that the absence of pain appeared to be directly related to the arrhythmia and not to the association of attacks of unconsciousness which seemed to be the cause in 5 of the 15 cases reported by Cookson (1942).

Shortness of breath was present in only 7 of the 21 cases; in 5 of these it was severe at the start of the illness when it assumed the form of cardiac asthma. Likewise, heart failure was present in only 6 , and subsequent cardioscopy confirmed the absence of pulmonary congestion in the remaining 15 cases.

Palpitation was both a presenting and lone symptom in 10; when this subsided following therapeutic slowing of the heart rate or a spontaneous return to normal rhythm, cardiac pain was still missing. The arrhythmia, rather than breathlessness, appeared to determine the absence of cardiac pain in patients in this group at the start of the illness although the continued absence of pain caused surprise and is without explanation.

Cardiac enlargement was prominent in one, moderate in 4 and slight or absent in 16 , so that its presence seemed in no wise to decide the onset of the abnormal rhythm or the absence of pain.

The clinical progress in 16 was satisfactory following orthodox therapy which included digitalization; it was poor in 5 , of whom 2 died.

The site of the infarct, as told from the electrocardiogram, was in the anterior wall of the left ventricle in 13 , in the posterior wall in 5 , affecting the left branch of the bundle in 2 , and the right branch in 1 . In 8 of the 11 patients in whom auricular fibrillation had persisted, the electrocardiographic diagnosis of cardiac infarction was straightforward (Fig. 1 and 2). The diagnosis became clearer in 10 cases after they had returned to normal rhythm (Fig. 3 and 4). In 3, one of 


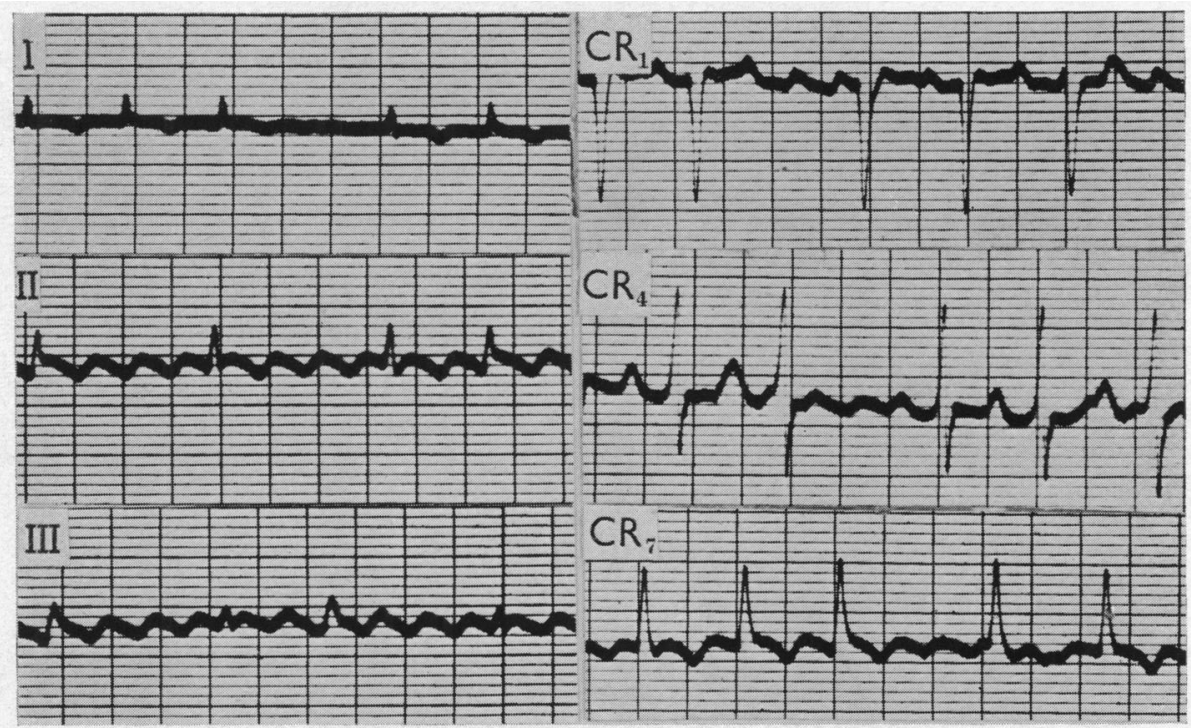

FIG. 1.-Cardiac infarction and auricular flutter. The arrhythmia does not conceal the inversion of the $T$ wave in lead $I$ although the same deformity in CR7 is less clear.
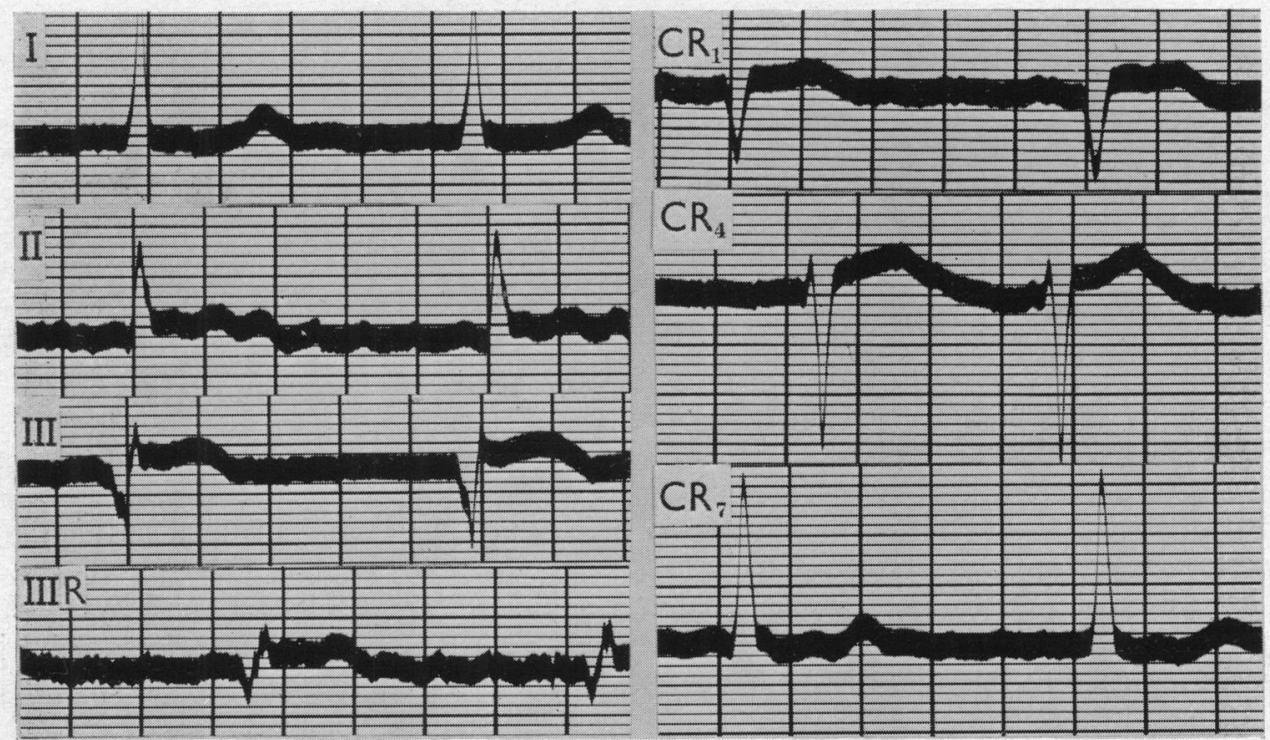

FIG. 2.-Cardiac infarction and auricular fibrillation. A Q wave, present in II, is deep and wide in III and IIIR, and the S-T segments are raised in the same leads. 


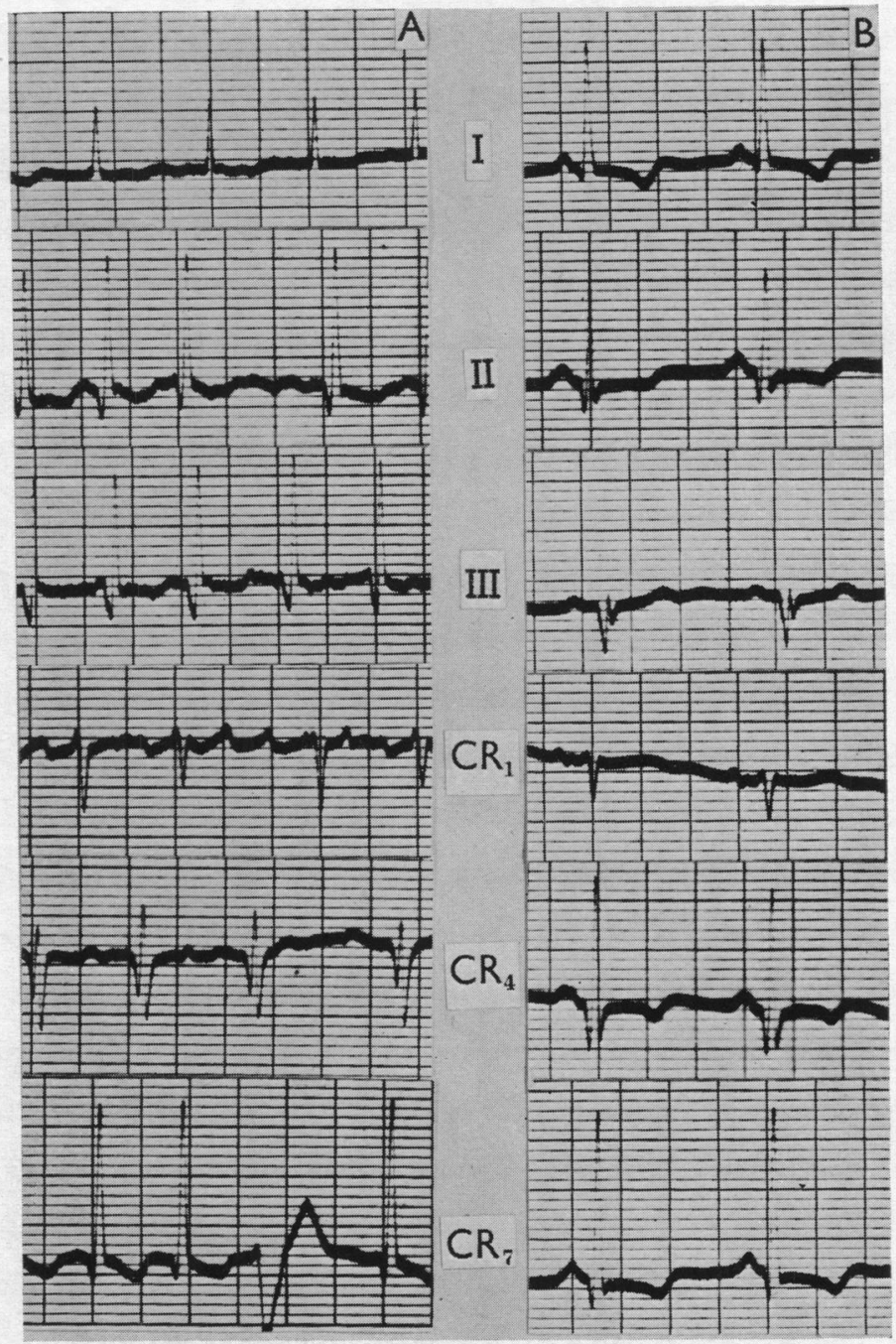

FIG. 3.-Cardiac infarction and auricular fibrillation. Fibrillation, present in (A), obscures the signs of infarction, but they are obvious in (B) where normal rhythm has been restored.

them with left bundle-branch block, and each showing the effects of digitalis medication, diagnosis was uncertain for a time.

We have been unable to find any firm opinion expressed on palpitation as a symptom that might prevent the appearance of pain in cardiac infarction. It was a prominent complaint in one of the cases reported by Boyd and Werblow (1937), but they did not allude to it as explaining the absence of pain in their patient.

\section{HYPERTENSION}

Arterial hypertension with sinus heart rhythm presented as the obvious form of cardiovascular disease in 9 of the 70 patients with painless cardiac infarction. There were 8 men and 1 woman. The average age was 56 years. 

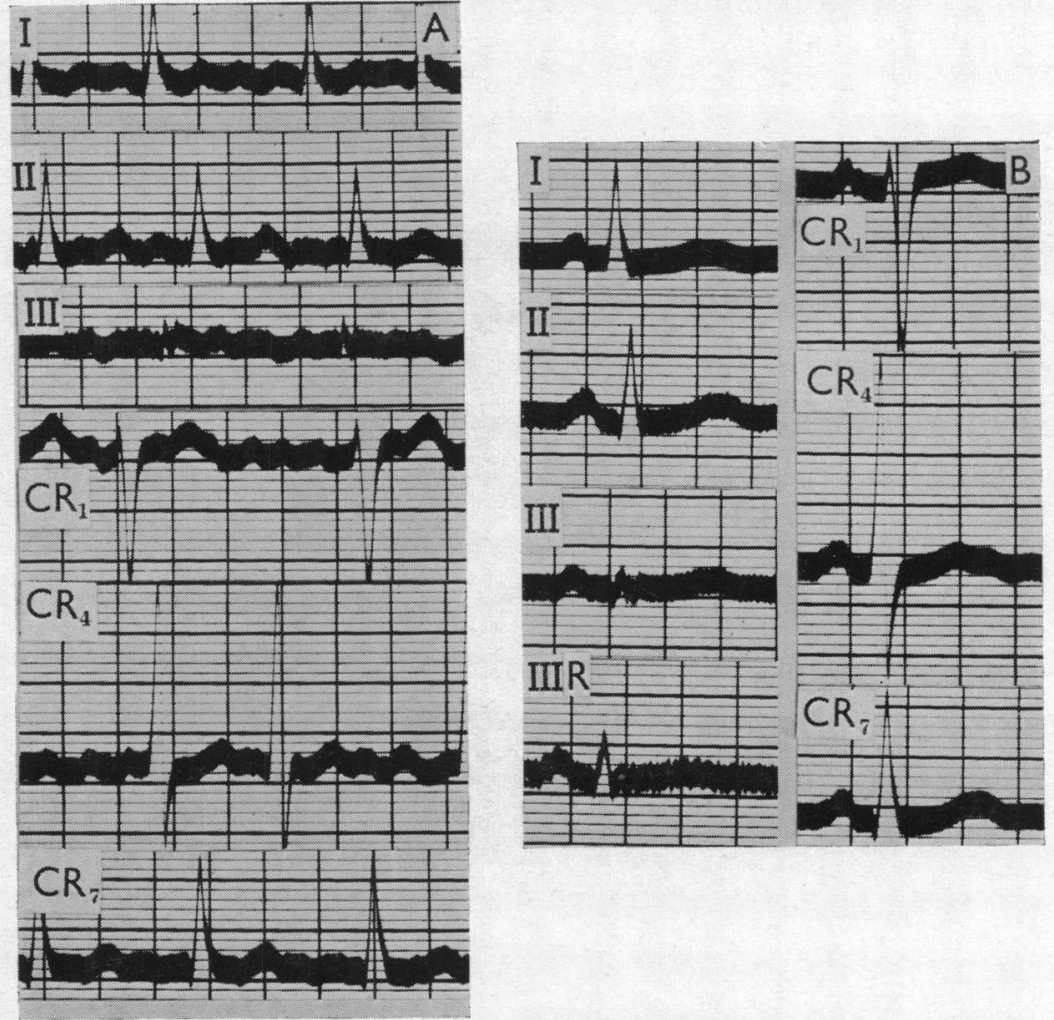

FIG. 4.-Cardiac infarction and auricular fibrillation. Fibrillation, present in (A), obscures the signs of infarction, but in (B), showing sinus rhythm, a low and blunt $T$ wave in leads, I, II, CR4 and CR7, confirms the presence of the restricted kind of cardiac infarction.

Breathlessness was present in 7 of the 9 patients, and in 3 it was severe and assumed the form of cardiac asthma. One of these died in the face of orthodox treatment which included digitalization and the use of mercurial diuretics, but progress in the other two was satisfactory. Four patients, who admitted to breathlessness on exertion, remained well, and along with two others without symptoms, had been referred for an opinion on hypertension discovered at a routine clinical examination; cardiac infarction in these cases was an unexpected electrocardiographic finding. One patient had uræmia and this was regarded as contributing to the absence of pain in his case.

Cardiac enlargement, present in each patient in this group, was prominent in 3 , while pulmonary congestion was a radiological finding in 4 patients. Triple heart rhythm was an auscultatory sign in 3 patients.

The blood pressure was raised in all, and neither the addition of cardiac infarction nor heart failure had subdued it to a normal level in any. Thus, the diastolic pressure was 110 or over in each of the 9 patients, 120 or over in seven, 130 or over in six and 150 in one.

Allusion has already been made to the difficulty experienced in the electrocardiographic diagnosis of cardiac infarction in the presence of left ventricular preponderance from associated hypertension. In 2 of the 9 patients, left bundle-branch block was not accompanied by additional cardiographic changes, like a $Q$ wave in CR7, which would name cardiac infarction as the cause of the bundle lesion; in one of them, however, cardiac infarction was confirmed at necropsy. In the other 7 patients, 
depression of the S-T segment in leads I and CR7 was present in each as an expression of left ventricular preponderance, and evidence of cardiac infarction was considered present if one or more of the following signs had been added to such S-T depression, namely inversion of the $T$ wave in lead I greater than in CR7 (Fig. 5), deformity of the T in CR4 as well as in CR7 (Fig. 6), or

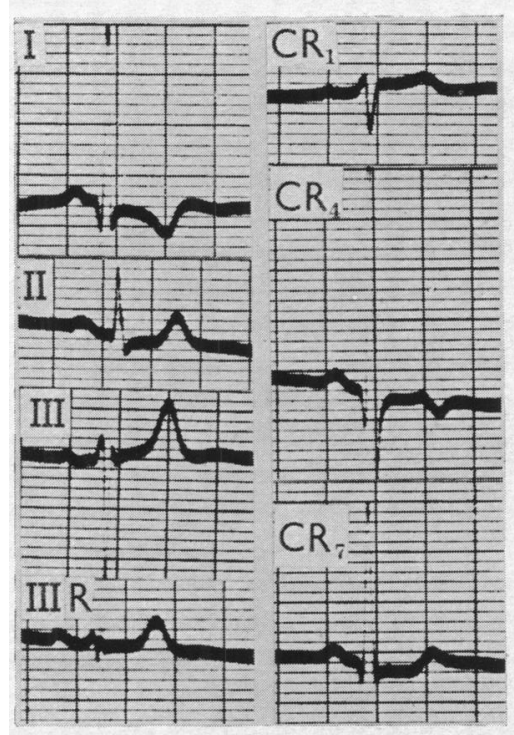

FIG. 5.-Cardiac infarction and hypertension. The T wave is inverted in lead $I$ and less in CR4. The $\mathbf{S}-\mathbf{T}$ is depressed in CR7 and the T in IIIR has lost height.

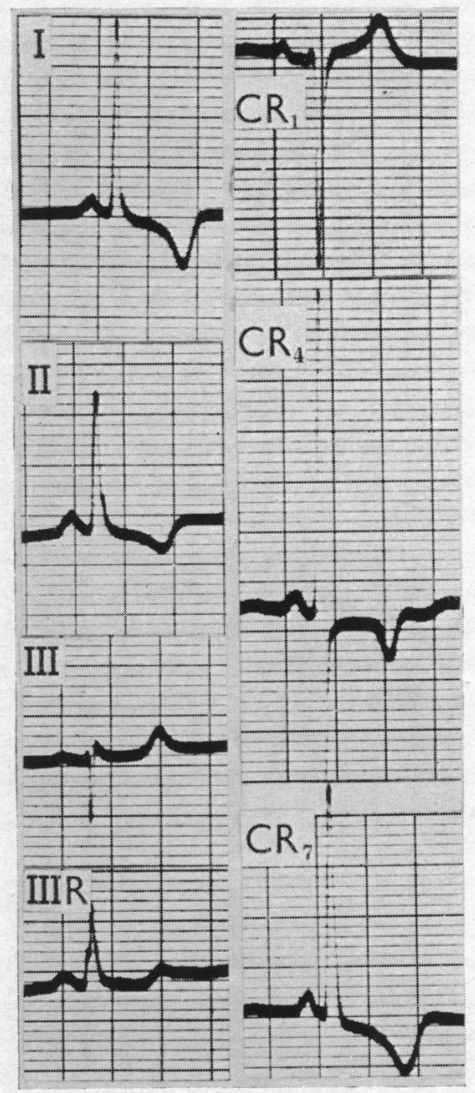

FIG. 6.-Cardiac infarction and hypertension. The $\mathrm{T}$ wave is inverted in CR4 as well as in I and CR7. The $\mathrm{S}-\mathrm{T}$ segment is depressed in IIIR but the $T$ wave is also inverted in lead II.

depression of the S-T segment in IIIR in the absence of digitalization and should the $\mathrm{T}$ wave in lead II be upright (Fig. 7). In two patients who died and who showed such cardiographic signs, the presence of both hypertension and cardiac infarction was confirmed at necropsy. Less definite signs than these were found in the tracings of some other patients with hypertension, but in the meantime it seemed prudent to exclude these from the series. There is need in the future to cement more securely the cardiographic diagnosis of cardiac infarction in cases that show left ventricular preponderance from hypertension.

Few observations dealing with painless cardiac infarction have directed attention to arterial hypertension as a factor that might contribute to the absence of pain, although Boyd and Werblow (1937) mentioned that a failure to recognize cardiac infarction in the absence of pain had usually happened in elderly subjects with known hypertension. Again, Yater et al. (1948), writing on 
coronary arterial disease in men aged 18 to 39 years, reported that the blood pressure was raised in 19 of the 23 examples who had not complained of pain.

Parkinson and Bedford (1928) were among the first to draw attention to the fact that dyspnœa might displace pain from the clinical picture of cardiac infarction. The effect of dyspnœa in subduing such pain has since been mentioned by others including Papp (1952) and Roseman (1954). When emphasizing the overshadowing of pain in cardiac infarction by paroxysms of cardiac asthma, most writers have spoken of the entry of such dyspnœa from heart failure complicating coronary arterial disease, and not as the outcome of hypertensive heart failure. Bedford (1939), commenting on the absence of pain in patients where dyspnœa overshadowed it, said that it was specially common in patients who already suffered from heart symptoms or even some degree of heart failure, and that cardiac asthma in a patient with a normal or low blood pressure and without aortic valve disease, suggested coronary occlusion. Similarly, Friedberg (1950) stated that the onset of sudden pulmonary œdema and intensification of heart failure pointed to cardiac infarction without pain. Gilchrist (1951) also mentioned that cardiac asthma in an elderly patient usually meant coronary disease.

\section{Conjoined Auricular Arrhythmia ANd Hypertension}

Since both auricular arrhythmia and hypertension were found separately as circumstances that favoured the absence of pain in cardiac infarction, it caused no surprise to find both conditions present side by side in some of the patients within this series. There were 7 such examples, 6 men and 1 woman. The nature of the arrhythmia was auricular fibrillation in every case.

Breathlessness, present in 6 patients, was severe in 5 at the onset of the illness when it assumed the form of cardiac asthma. Palpitation was the uppermost symptom in only one patient.

There was either moderate or greater cardiac enlargement in every case, and similarly pulmonary congestion was seen at cardioscopy in each. Triple heart rhythm was present in only three as treatment was under way in each patient before we examined them.

In spite of the presence of cardiac infarction, and of heart failure in most of the cases, the diastolic blood pressure was 110 or over in 7,115 or over in 6,120 or over in 5,130 or over in 3 , and 150 in one.

Hypertension with or without heart failure appeared to account for the absence of pain in most patients within this group, and only in one was arrhythmia considered to be responsible.

Progress in every patient has been unsatisfactory in the face of adequate treatment. Five of the patients have died and the remaining two are precariously ill.

The electrocardiographic diagnosis of cardiac infarction in patients in this group was frustrated by the persistence of auricular fibrillation in 3 , by left ventricular preponderance, and by digitalization which had been started in most of them before the diagnosis of infarction was considered and while heart failure alone was thought to be operating. The electrocardiographic diagnosis was possible in 5, and although it remained doubtful and presumptive in the other two, the presence of cardiac infarction was confirmed at necropsy in both cases.

\section{RESTRICTED CARDIAC INFARCTION}

The electrocardiographic changes that follow salient or extensive cardiac infarction are plain to see, but when the myocardial injury is restricted or limited in its distribution the changes are less obvious and in many instances they escape detection if they are not deliberately sought (Evans and McRae, 1952). The pain associated with such lesser changes is not always correspondingly less severe except that it is never accompanied by shock or heart failure, and only occasionally by arrhythmia, triple heart rhythm, or slight cardiac enlargement. It was expected, therefore, that instances of restricted infarction would appear in our series of painless infarction.

There were 26 such patients, 19 men and 7 women. The average age was 55 years. The myocardial injury was discovered fortuitously for none came with serious symptoms nor showed any abnormal signs except for triple rhythm in 3. They attended for a medical examination which 
happened to include an electrocardiogram. The deliberate omission of any intentional search for electrocardiographic abnormalities in patients without chest pain, and in whom for that reason cardiac infarction is not suspected, accounts for the relatively small proportion of such cases in our series. It is likely that routine electrocardiography in uncomplaining elderly subjects over the age of 60 , would increase substantially the number of patients in this group. In our opinion, however, any deliberate search for such cases would be unwise unless intended as a limited inquiry carried out as part of a research project.

The diagnosis of restricted infarction in our cases rested on the following cardiographic findings: depression of the S-T segment in 15, a low T wave in leads I and CR7 in 5, a bifid T wave in CR4 in one, and the appearance of a $Q$ wave in lead IIIR, which had been absent in III, in 5 patients. If the significance of any of these changes remained in doubt the tracing was repeated after strenuous exercise when the validity of the cardiographic sign was confirmed.

The progress in all 26 patients had been satisfactory when they were first examined. Subsequently, one patient experienced extension of his cardiac infarction, with the exhibition of typical cardiac pain. Another died of typhoid when abroad and there was no necropsy. A third died of a cerebral accident and at necropsy extensive coronary atheroma was associated with slight changes in the myocardium. A fourth presented minor functional symptoms at his first visit when a routine electrocardiogram showed restricted cardiac infarction; two years later he was re-examined a fortnight after experiencing a sense of tightness in the chest and on that occasion the electrocardiogram showed the signs of salient infarction providing evidence of extension of the original infarct.

Sutton and Lueth (1930) and Sutton (1931), from their experiments in the dog and from their experience with coronary arterial disease in man, stated that the pathway of pain, arising from faulty nutrition of the heart muscle, was by way of the nerve fibres that lie in the adventitia of the coronary arteries. They stated that the absence of pain which may be met with, even in the presence of extensive coronary disease, was due to an efficient anastomosis between branches of the coronary arteries, and that the severity of the pain varied with the degree of closure of the artery and with its size. Again, Sutton and Brandes (1931) opined that myocardial function, and similarly the presence of cardiac pain in coronary atherosclerosis, depended upon blood flow and not on scarring, and varied with the efficiency of the anastomosis. We agree with their conclusions and emphasize that in patients with restricted cardiac infarction it is the tardy progress of the infarction that explains the absence of pain and not the smallness of the infarct, for in a separate series of 328 patients with restricted infarction collected by Evans (1956) there was cardiac pain which was indistinguishable from the pain associated with salient cardiac infarction that showed obvious cardiographic changes.

One patient, a man, aged 53 years, who had been accepted for the series was later excluded; although without any complaints he had applied for a routine medical examination following the unexpected death of a friend. The finding of a bifid $T$ wave caused surprise and was accepted as evidence of a myocardial injury from coronary arterial disease which had formed in the absence of pain. Extension of the deformity in an exercise electrocardiogram (Fig. 8) appeared to confirm this view. He reported for re-examination a year later and was still symptom free. A normal electrocardiogram on this occasion gave rise to suspicion as to the validity of the initial diagnosis of painless cardiac infarction, and some other cause of the cardiographic deformity was sought. The alternate explanation of the blemish in the first tracing came with the patient's confession, which followed direct questioning, that for many years prior to his first examination his daily consumption of whisky had exceeded 20 ounces $(570 \mathrm{ml}$.). It is likely, therefore, that alcoholic myocarditis had caused the initial changes in the electrocardiogram which had resolved when the patient had assumed more temperate habits. This example points the lesson that when lesser electrocardiographic changes recover wholly a temporary myocardial injury has caused them, and equally that if such changes persist and spread, restricted cardiac infarction from coronary arterial disease is the cause even in the absence of cardiac pain when the process has been a gradual one. 


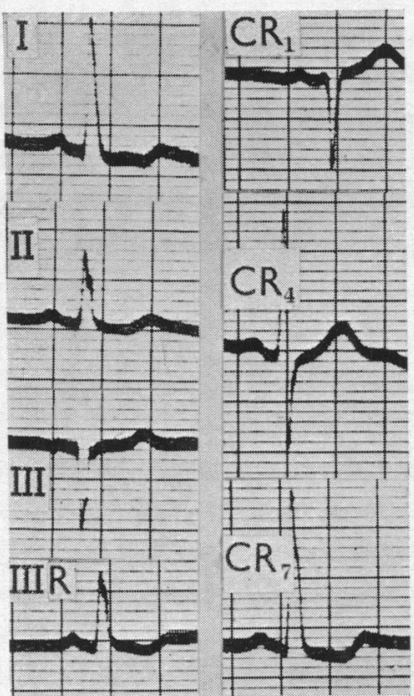

FIG. 7.-Cardiac infarction and hypertension. There is greater depression of the S-T segment in CR7 than in I. The $T$ wave is upright in lead II and the $\mathbf{S}-\mathbf{T}$ is depressed in IIIR.

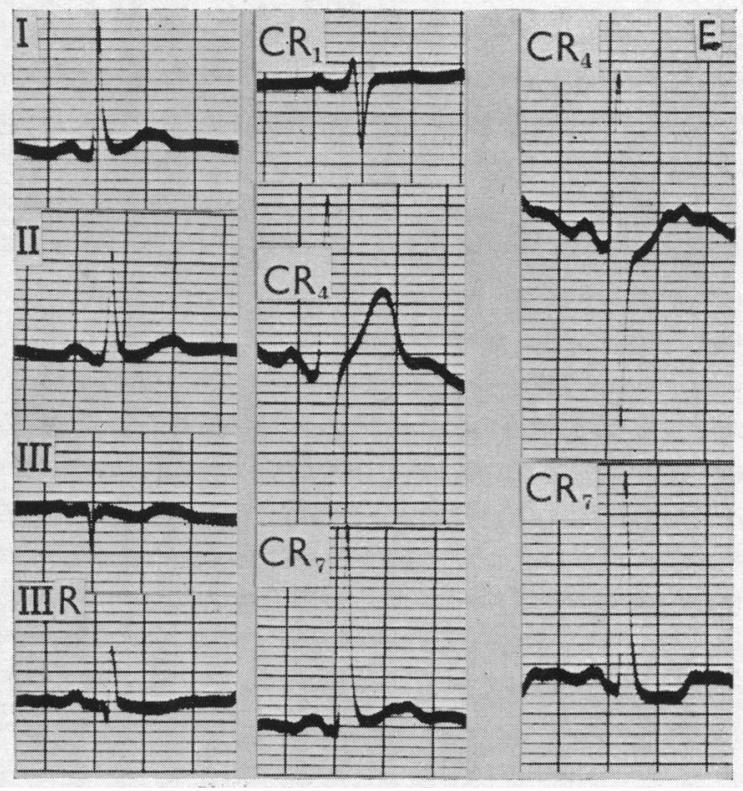

FIG. 8.-Aichoholic myocarditis. In the resting electrocardiogram the $T$ wave is blunt in leads I and CR7; the exercise tracing $(\mathrm{E})$ is regarded as abnormal.

\section{OTher Circumstances}

When the absence of pain in cardiac infarction had been attributed either to auricular arrhythmia or hypertension in 37 patients and had been found as a feature of 26 patients with restricted cardiac infarction, there remained 7 in whom some other contingency appeared to be responsible for such painlessness. The circumstances that might have contributed to the absence of pain in these patients will now be separately examined.

Stokes-Adams Disease. Although 4 patients are considered under this head, if the definition of the syndrome is strictly adhered to as a clinical state where unconsciousness is associated with heart block, it is doubtful whether any were true examples of it.

The illness in two patients was heralded by a syncopal attack, and both denied chest pain after recovering consciousness. Neither patient was in a state of collapse when emerging from the attack. The electrocardiogram, which exhibited obvious changes from cardiac infarction, showed no kind of heart block. Subsequently, when both patients were re-examined, no further syncopal attacks had taken place, the cardiogram continued to show sinus rhythm and the same frank inversion of $T$ waves, while cardiac pain was still absent. If these two patients are to be regarded as examples of Stokes-Adams disease, the heart block must have been of the transient variety.

The third patient in whom the electrocardiogram confirmed the presence of complete heart block and unequivocal changes of cardiac infarction, had never experienced unconsciousness. There was only moderate enlargement of the heart when viewed by cardioscopy, and there was no pulmonary congestion.

The fourth patient was examined because of recent giddiness which visited him unawares causing him to sway and lose his balance, but he denied ever being unconscious. No abnormal physical signs were uncovered during clinical examination, and it caused surprise to find characteristic electrocardiographic changes of cardiac infarction with sinus rhythm. Here again, there may 
have been transient heart block during the attacks of severe vertigo, but proof of this was not obtained, and his progress has been satisfactory since the paroxysms ceased.

Fainting or collapse had taken place in 4 out of 17 patients with painless cardiac infarction reported by Pollard and Harvell (1940), while Cookson (1942) observed a syncopal or epileptiform episode in 15 patients with recent cardiac infarction in whom pain was either slight or absent. Friedberg (1950) also mentioned dizziness as the chief symptom in many patients in whom pain was absent.

Vomiting. Although vomiting was a noticeable symptom in four patients, two have been included in other groups, for in one arrhythmia rather than vomiting was considered responsible for the absence of cardiac pain, while in the other patient with complete heart block vomiting might have been a factor contributing to keep the pain at bay.

In two cases, however, severe vomiting was the only presenting symptom. One patient, a woman, aged 62 years, was taken ill with unexpected vomiting while attending a cinema. She vomited twice before she could leave the building; there was no pain and she walked home where severe vomiting recurred. That evening she felt very ill and fainted four times. Thereafter, she improved, but two months later she experienced undue breathlessness on walking. When examined there was triple heart rhythm, moderate generalized cardiac enlargement, and pulmonary congestion, and obvious electrocardiographic signs of cardiac infarction. She responded well to treatment with rest, digitalization, and four injections of a mercurial diuretic. The second patient was a woman, aged 78 years, who was taken ill with sudden and severe vomiting; when her medical attendant arrived the vomiting had ceased, but as her pulse was rather small and she seemed frail, he gave instructions that he should be recalled if her condition deteriorated. A few hours later, vomiting again set in, and she died soon after. She had denied emphatically that there was any pain in the chest or elsewhere. At necropsy recent cardiac infarction was found to have resulted from coronary thrombosis complicating coronary atheroma.

Although sudden nausea and vomiting has seldom been named as a symptom that might . obscure pain in cardiac infarction, Pollard and Harvell (1940) found it in 5 among their 17 cases of painless infarction.

Cerebral Embolism. Dozzi (1937) wrote about cerebral embolism or thrombosis as another circumstance that might obscure a history of pain in cardiac infarction. He pointed out that in this event the diagnosis was directed to the cerebral vascular accident, and the primary cardiac lesion was overlooked. Thus, in 1000 consecutive cadavers he found 12 instances of cerebral thrombosis or embolism among 41 cases of cardiac infarction, and in only two had the heart condition been recognized. This frequent association of the two lesions suggested that in all cases of cerebral infarction, the possibility of cardiac infarction and intracardiac thrombosis as the source of the embolism, should be kept in mind. Levine (1945) also emphasized the importance of this association, stating that when a sudden hemiplegia takes place in a patient whose blood pressure is not remarkably raised, the diagnosis of cerebral hæmorrhage is too often made, for in some of these cases, unsuspected cardiac infarction may be the source of the embolism.

The fact that only one such example of painless cardiac infarction appears in our series is not meant to emphasize the rarity of this association because our patients were assembled on account of symptoms that more often pointed to a fault in the heart rather than the brain; moreover they form a clinical group rather than necropsy material. Our patient was a man, aged 54 years, who developed a right hemiplegia overnight. He woke up at the usual time and became alarmed when he found that his right arm and leg were paralysed and his speech affected; he had not experienced any pain in the chest nor did it develop during convalescence. He was referred for examination of the heart because of the absence of hypertension and other known causes of a cerebral accident, and the electrocardiogram showed characteristic changes of cardiac infarction.

The Unreliable Witness. We anticipated that amnesia following heavy narcosis, induced by morphine at the start of the illness, might be responsible for the absence of cardiac pain in a number 
of patients. Indeed, such instances came to our notice, but since one of the conditions for acceptance into the series stipulated that a friend or attending physician, who might have witnessed the start of the illness, had also to testify to the absence of pain, these were rejected as examples of painless cardiac infarction. One patient, included in the hypertension group, suffered from uræmia, and this might have dulled his appreciation of pain in the chest, if it had been there.

There was, however, one outstanding example of the wilful witness who deliberately suppressed a history of cardiac pain in order to gain profit from a medical certificate testifying to his satisfactory state of health. He was a man, aged 56 years, who had been referred for special examination connected with his application for admission to a superannuation scheme. His acceptance for the scheme depended on a medical report which would endorce his fitness for work, and his likelihood to continue his duties as a servant of a Borough Council until he reached the age of 65 years. Under these circumstances the patient found it to his advantage to hide his symptoms so that even on direct questioning he denied ever experiencing chest pain. The electrocardiogram, however, testified to the undoubted presence of cardiac infarction (Fig. 9). Later, when his admission to a superannuation scheme had been rejected he confessed to experiencing typical cardiac pain.

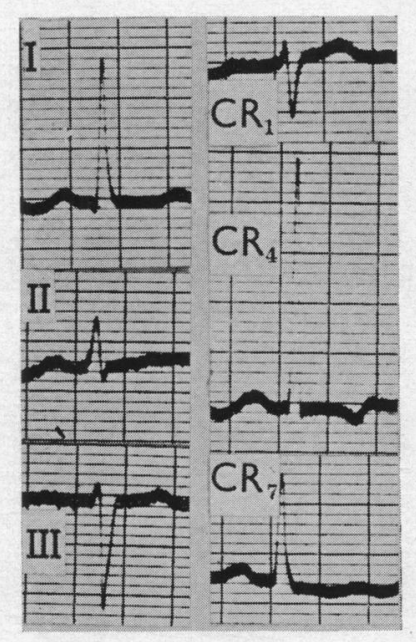

FIG. 9.-Cardiac infarction. The $T$ wave is flat in leads I and CR7, and is inverted in CR4.

The INCIDENCE OF PAINLESS CARdiaC INFARCTION

Considerable discrepancy is found among the figures given by the several authors who have written on the frequency with which pain is absent in patients with cardiac infarction. Many have suggested that the syndrome is a common one. Thus, Davis (1932) found 38 per cent without pain among 76 patients, Saphir et al. (1935) 38 per cent among 34 cases, Boyd and Werblow (1937) 33 per cent among 127 cases, Bean (1938) 28 per cent among 300 cases, and Gorham and Martin (1938) 40 per cent among 100 cases. Other authors have met with the condition less often. Thus, Master et al. (1937) found only 8 examples of painless cardiac infarction among 530 patients, Babey (1939) one among 116 cases, Pollard and Harvell (1940) 32 among 375 cases, Warner (1951) none among 200 cases, Roseman (1954) 10 among 220 cases, and Gerther et al. (1954) 4 among 200 young adults.

Four circumstances materially affect figures denoting the incidence of painless cardiac infarction. First, if pain is so defined as to exclude such sensations described by patients as discomfort, tightness, pressure, and indigestion, the incidence of this syndrome will be inevitably high. Secondly, if the 
data are collected from case records not compiled under the personal supervision of the author, a statement on the absence of pain is likely to be unreliable and its incidence too high. Even a denial of any pain should be met with direct questioning about the presence of discomfort while the observer's hand rests inquiringly on the patient's chest; if a confession of pain is still not forthcoming a final appeal should be directed to a relative or doctor who might have witnessed the initial attack. Thirdly, little credence should be given to the evidence of a patient taken sometime after the event, or when the shock of a salient cardiac infarction is not long passed, or while recovering from the effects of a major operation or recent narcosis; a patient can be too ill to complain of pain. Fourthly, as our knowledge of the electrocardiographic signs of restricted cardiac infarction increases, and the practice of recording cardiograms in uncomplaining elderly subjects becomes commonplace, so will instances of painless cardiac infarction multiply in number.

For these reasons we do not intend to give the incidence of the condition as it appeared in our series, but instead we wish to emphasize the circumstances that favour the absence of pain in cardiac infarction, so that our increased awareness of the likely presence of this contingency should lead to its readier recognition and to the immediate treatment appropriate to it.

\section{The Cause of Painlessness in Cardiac Infarction}

Even when the circumstances associated with painless cardiac infarction are known, the precise way in which these work to exclude pain is not understood. Libman (1926) and Carr (1935) considered that patients with painless cardiac infarction were insensitive to pain, and Libman devised a test intended to establish this hyposensitivity in the individual, where the painful response was estimated when the thumb pressed the great auricular nerve against the styloid process. Herrick (1929) opined that certain areas of the heart were silent or less sensitive than others, or that a gradual narrowing of an artery slowly destroyed vessels, nerves and functioning muscles, causing anæsthesia in the part, so that the final complete obstruction happened less suddenly and in prepared ground.

Wearn (1923) and Hamman (1934) stated that when cardiac infarction supervened in a patient with pre-existing signs and symptoms of heart failure, pain may be absent, and Hay (1933) considered that pain was likely to be absent in the second or third attack of infarction. Bruenn and others (1936) on the other hand believed that those patients with no symptoms prior to the acute episode were most likely to experience painless cardiac infarction.

We found that in the group of patients in whom auricular arrhythmia appeared to have determined the absence of pain, the heart had usually remained unaffected until the onset of the illness. Thus, among the 21 patients, cardioscopy could not find any significant cardiac enlargement in 16 , nor pulmonary congestion as an early sign of heart failure in 15 . Indeed, in this group the painlessness of the infarct was independent of the presence of previous heart disease and was the direct result of the arrhythmia. Moreover, it was never apparent that the symptom of palpitation had overshadowed the symptom of pain, but rather had it eclipsed or prevented its very inception.

The combined groups of patients with hypertension and hypertension conjoined with auricular arrhythmia, provided 16 examples of painless cardiac infarction, and in these we examined the mechanism whereby pain was absent, with reference to the influence that might be exerted by cardiac enlargement or by breathlessness and heart failure. Enlargement of the left ventricle with left ventricular preponderance in the electrocardiogram was present in each of the 16 cases and in 6 there was great enlargement. Breathlessness was absent in 3 while in 8 of the remaining 13 cases it took the form of cardiac asthma for a time, but even when this symptom abated following treatment and the patient became ambulatory, cardiac pain remained absent. Pulmonary congestion, elicited at cardioscopy, was present in 11 and absent in the other 5 . Here, too, it became clear that the limitation of activity imposed on a patient did not explain the absence of pain because it continued to be absent when effective treatment had enabled the patient to return to greater physical activities. The presence of heart failure, therefore, in no wise determined the absence of pain in cardiac infarction. It was evident, too, that breathlessness did not overshadow the pain, unless in 
such cases as were too ill for a time to make their complaints known, where it will remain difficult to pronounce on the precise circumstances that are operating. The absence of pain in this group appears to be related to the increased muscle mass which is present in hypertension and which may determine a slower rate of muscle necrosis resulting from infarction which follows coronary occlusion.

In the largest group of patients without pain, namely those with restricted cardiac infarction, we believe that the absence of pain is directly related to the tardy closure of the atherosclerotic coronary branches, a view put forward first by Sutton (Sutton and Lueth, 1930; Sutton, 1931) and later by Mullen (1934). Keefer and Resnik (1928) also thought that in patients with slow infarction the painful impulse might not be sufficiently intense to reach the sensorium.

\section{SummaRY AND CONCLUSIONS}

Among patients with cardiac infarction examined in private and hospital practice during the past five years there were 70, 56 men and 14 women, in whom pain was absent.

An ache, discomfort, a feeling of pressure or tightness or indigestion, sensations that a patient might regard as akin to pain, were accepted by us to mean pain, and they, too, were absent in the 70 cases that we describe. Moreover, we required each patient to deny the presence of such symptoms following direct questioning while the observer's hand rested on the chest suggesting the place of the discomfort. Further, should the illness have started unexpectedly we sought confirmation of the absence of pain from a relative, friend, or attending physician, who might have witnessed its onset. There was one patient who wilfully denied the experience of chest pain on effort, in an attempt to gain profit from a favourable medical report. Lastly, the electrocardiogram had to show indisputable evidence of cardiac infarction.

Foremost among the conditions that appeared to determine the absence of pain, and featuring in 21 cases, was auricular arrhythmia, usually in the form of auricular fibrillation and sometimes auricular tachycardia. Such arrhythmia occasionally frustrated the electrocardiographic diagnosis of cardiac infarction, but when sinus rhythm was spontaneously restored, as happened in one-half of the cases, the graphic interpretation became easier; even then the patient, during increased physical activities, remained free from chest pain.

Hypertension, with normal sinus rhythm in 9 and auricular fibrillation in 7 , also proved a deterrent to pain in cardiac infarction. Although many of these suffered from paroxysms of cardiac asthma, we do not attribute the absence of pain to any overshadowing of the symptom by breathlessness, but consider that a tardiness of the process of infarction in a heart muscle enlarged in the course of hypertension was mainly instrumental in preventing the advent of pain.

In 26 patients the absence of pain was associated with restricted infarction which had been discovered fortuitously at an examination that happened to include electrocardiography. This number would have increased manyfold if a cardiogram had been recorded deliberately in uncomplaining subjects over the age of 60 years. It is known that patients with this limited kind of infarction commonly suffer characteristic cardiac pain, and we believe that the absence of pain is determined not by the smallness of the infarct, but by the slowness of infarction, which in turn depends on the rate of arterial closure, the limitation of coronary blood flow, and the efficiency of the collateral circulation.

Other circumstances proving inimical to pain in cardiac infarction appeared less frequently; these included Stokes-Adams disease which may have played a part in 4 patients, severe vomiting which supplanted pain in 2 cases, and cerebral embolism which appeared to have subdued pain in one patient.

In the uncovering of disease, to know is to seek, and to seek is to find. To know the circumstances that favour painlessness in cardiac infarction is to seek the condition in elderly subjects with auricular arrhythmia of uncertain origin, or with hypertension. To find it present in any patient affects the outlook, and invites appropriate treatment early in the illness. 
We are indebted to Dr. D. M. Blend for placing at our disposal the careful notes he had compiled in the case of his patient in whom severe vomiting was the only symptom of cardiac infarction which caused her death within a short time of the start of her illness.

\section{REFERENCES}

Babey, A. M. (1939). New Eng. J. Med., 220, 410.

Bean, W. B. (1938). Ann. intern. Med., 11, 2086.

Bedford, D. E. (1939). Trans. Med. Soc. Lond., 62, 165.

Boyd, L. J., and Werblow, S. C. (1937). Amer. J. med. Sci., 194, 814.

Bruenn, H. G., Turner, K. B., and Levy, R. L. (1936). Amer. Heart J., 11, 34.

Carr, J. G. (1935). Illinois med. J., 68, 155.

Cookson, H. (1942). Brit. Heart J., 4, 163.

Davis, N. S. (1932). J. Amer. med. Ass., 98, 1806.

Dozzi, D. L. (1937). Amer. J. med. Sci., 194, 824.

Editorial (1938). Lancet, 1, 95.

Evans, W. (1956). Cardiology. Butterworths, London, 2nd ed.

, and McRae, C. (1952). Brit. Heart J., 14, 429.

Friedberg, C. K. (1950). Diseases of the Heart. Saunders \& Co., Phil.

Gairdner, W. T. (1891). Lancet, 1, 604.

Gallavardin, L. (1921). J. Méd. Lyon, $2,913$.

Gerther, M. M., White, P. D. (1954). Coronary Heart Disease in Young Adults. Harvard Univ. Press.

Gilchrist, A. R. (1951). Brit. med. J., 1, 874 and 937.

Gorham, L. W., and Martin, S. J. (1938). Arch. intern. Med., 62, 821.

Hamman, L. (1934). Ann. intern. Med., 8, 417.

Hay, J. (1933). Lancet, $2,787$.

Herrick, J. B. (1912). J. Amer. med. Ass., 59, 2015.

Keefer, C. S., and Resnik, W. H. (1928). Arch. intern. Med., 41, 769.

Levine, S. (1945). Clinical Heart Disease. Saunders \& Co., Lond. 3rd ed.

Libman, E. (1926). Trans. Ass. Amer. Physicians, 41, 305.

Master, A. M., Dack, S., and Jaffe, H. K. (1937). J. Amer. med. Ass., 109, 546.

Mullen, J. P. (1934). West Virginia med. J., 30, 1.

Obrastzow, W. P., and Straschesko, N. D. (1910). Z. klin. Med., 71, 116.

Papp, C. (1952). Brit. Heart J., 14, 250.

Parkinson, J., and Bedford, D. E. (1928). Lancet, 1, 4.

Pollard, H. M., and Harvell, T. H. (1940). Amer. J. med. Sci., 199, 628.

Roseman, M. D. (1954). Ann. intern. Med., 41, 1.

Saphir, O., Priest, W. S., Hamburger, W. W., and Katz, L. N. (1935). Amer. Heart J., 10, 762.

Sutton, D. C. (1931). J. Amer. med. Ass., 97, 1369.

and Brandes, W. W. (1931). J. Lab. clin. Med., 16, 1185.

-, and Lueth, H. C. (1930). Arch. intern. Med., 45, 82.

Warner, H. R. (1951). Minnesota Med., 34, 49.

Wearn, J. T. (1923). Amer. J. med. Sci., 165, 250.

Yater, W. M., Traum, A. M., Brown, W. G., Fitzgerald, R. P., Geisler, M. A., and Wilcox, B. B. (1948). Amer. Heart J., 36, 334. 